\title{
Balance of Internal Drive, Ego and Super Ego through Self-Hypnosis
}

\author{
Cittoor Girija Navaneedhan \\ Sree Sastha College of Education, Chennai, India \\ Email: girija60@rediffmail.com
}

Received September 2, 2011; revised November 21, 2011; accepted December 7, 2011

\begin{abstract}
The paper discusses about the influence of Self-Hypnosis on the three important qualities determining the personality trait of an individual namely: Internal Drive (ID), Ego and Super Ego. Self-Hypnosis is a technique that regulates one's own mind by setting attributes to achieve the basic goals in life having a wider range of variation from one individual to another. There is a constant conflict occurring in an individual's mind between ID, Ego, and Super Ego throughout his life time till death. The paper work attempts to bring certain facts about the ID, Ego and Super Ego and how to balance between the three through Self-Hypnosis.
\end{abstract}

Keywords: Internal Drive; Ego; Super Ego; Conflict and Self-Hypnosis

\section{Introduction}

Internal Drive is defined as the unorganized behavior of an individual trying to influence the mind towards basic needs. It is inaccessible part of our personality resulting from neurotic symptoms characterizing negative character and can be described only as a contrast to the Ego. It is filled with energy reaching from the instincts, but has no organization, produces no collective will, but only striving to bring about the satisfaction of the instinctual needs subject to the observance of the pleasure principle. In the ID contrary impulses exist side by side, without cancelling each other out, thus psychic apparatus begins, at birth, as an undifferentiated ID part of which then develops into a structured Ego. It is very well known fact that the mind of a newborn child is id-ridden, hence its immediate need is the satisfaction of being in the mother's care. The ID is responsible for individual's basic drives and knows no judgments of value, no good evil, no morality etc. It is regarded as the great reservoir of the instinctive drive to create-the life instincts that are crucial to pleasurable survival. Freud [1] proposed in his later career of life the death instinct that an individual experiences is the result of chaos of mind due to it. The Ego comprises that organized part of the personality structure that includes defensive, perceptual, intellectual-cognitive, and executive functions. According to Freud the word Ego means a sense of self, but later considered it as a set of psychic functions such as judgment, tolerance, reality-testing, control, planning, defense, synthesis of information, intellectual functioning, and memory. It helps an individual to organize thoughts and make sense of the world around $\mathrm{him} /$ her. The Ego is that part of the ID which has been modified by the direct influence of the external world. Ego is thought to serve three severe masters, the external world, the Super-Ego and the ID. Its task is to find a balance between primitive drives and reality while satisfying the ID and Super-Ego. Its main concern is with the individual's safety and allows some of the ID's desires to be expressed, but only when consequences of these actions are marginal. Thus the Ego, driven by the ID, confined by the Super-Ego, repulsed by reality, struggles in bringing about harmony among the forces and influences working in and upon it and readily breaks out in anxiety in three different ways-realistic anxiety regarding the external world, moral anxiety regarding the Super-Ego, and neurotic anxiety regarding the strength of the passions in the ID. It has to do its best to suit all three. It is said, however, that the Ego seems to be more loyal to the ID, preferring to gloss over the finer details of reality to minimize conflicts while pretending to have a regard for reality. But the Super-Ego is constantly watching every one of the Ego's moves and punishes it with feelings of guilt, anxiety, and inferiority. Freud developed his concept of the Super-Ego from an earlier combination of the Ego ideal and the special psychical agency which performs the task of seeing that basic satisfaction from the Ego ideal. Installation of the Super-Ego can be described as a successful instance of identification with the parental care. As the development proceeds the Super-Ego also takes on the influence of people who were parentseducators, teachers, people chosen as ideal models. 
The Super-Ego aims for perfection. It comprises of the personality structure, mainly which includes the individual's Ego ideal, spiritual goals, and the psychic agency (commonly called "conscience") that criticizes and prohibits his or her drives, fantasies, feelings, and actions. The Super-Ego can be thought of as a type of conscience that punishes misbehavior with feelings of guilt. For example: having extra-marital affairs.

The Super-Ego works in contradiction to the ID. The Super-Ego strives to act in a socially appropriate manner, whereas the ID just wants instant self-gratification. The Super-Ego controls our sense of right, wrong and guilt. It helps us fit into society by getting us to act in socially acceptable ways. As the Super-Ego tends to oppose the ID, the Ego has a hard time in reconciling the two.

The Super-Ego tends to stand in opposition to the desires of the ID because of their conflicting objectives, and its aggressiveness towards the Ego. The Super-Ego acts as the conscience, maintaining the sense of morality and proscription of taboos. The Super-Ego and the Ego are the product of two key factors: the state of helplessness of the child and the Oedipus complex.

\section{Self-Hypnosis, ID, Ego and Super Ego}

Self-Hypnosis is a mind full technique one could practice regularly to full fill a set goal. The present paper discusses how to balance ID, Ego and super Ego by the regular practice of Self-Hypnosis. Emile Coue (2010) [2] referred to Self-Hypnosis coupled with Affirmations which could reduce the conflict of ID, bringing a balance between Ego and Super Ego as the Affirmations are specific, positive statements that an individual states to himself/ herself in order to change some aspect of his/her own self. For example saying "I am clever and people like me" is an affirmation. It is designed to convince one's own self that this is true. The best known affirmation is probably according to Emile Coue's (2010) [2] famous advice is telling of one's own self "Every day in every way, I am getting better and better". If this statement is repeatedly told to one's self that he/she is confident, that he/she is a winner, that people like them, then it would become true. It works because once an individual unconsciously believe something, that belief is expressed in an individual's body language and speech patterns so that other people would react to those signals. By means of affirmations one could overcome the primitive instinct ID favoring Ego and Super Ego which enables the individual to develop a calm state of mind reducing the internal conflict which could be corrected by Self-Hypnosis with affirmations. As the above mentioned disorders result due to the imbalance between the ID, Ego and Superego, Self hypnosis being a technique which is individualistic in nature of each person's mind setting. There are many hypnotherapeutic evidences about strengthening one's own Ego by visualization resulting in great success. This process is called as "mental rehearsal" is a means of practicing for the "event" in our mind's eye over and over again prior to any performance. For e.g. A concert pianist waiting in the wings to play their competition piece mentally rehearses their finger movements over and over again not only to build confidence but to practically and literally "train" the mind and body. Visualization can dramatically improve results. Apart from visualization evidences show Ego strengthening by Affirmations. These Affirmations by Self-Hypnosis Ego strengthening to improve concentration helps clients to focus more precisely on the goal. Thus it could be very well suggested that an Ego strengthening hypnosis script is designed to help clients develop an unflappable positive attitude. Thus Ego strengthening hypnosis script helps to create an attitude transformation capable of protecting clients from their own irritation, anger, or discouragement and provides the right kind of positive affirmations to immunize clients from negative emotional reactions that brings down their power. In order to achieve better success by means of eliminating thoughts or fears that weakens concentration and therefore the individual's potential.

\subsection{Objective of the Study}

To find the effectiveness of Self-Hypnosis technique coupled with affirmations in bringing a balance between ID, Ego and Super Ego.

\subsection{Aim of the Study}

The study is focused on bachelor of Education students as they are constantly involved in shaping the personality of children. Therefore, it is necessary to train teacher trainees in self hypnosis technique so that a balance between ID, Ego and Super Ego would transform them as balanced individuals.

\subsection{Sample}

The sample consists of 10 Bachelor of Education students in the age group 22 - 40 years. Bachelor of Education involves a teacher training course, the students are more prone to clash between ID, Ego and super Ego. In order to balance between ID, Ego and super Ego, a regular practice of Self hypnosis would help them to become a balanced individual.

\subsection{Research Question}

Is Self-Hypnosis an effective technique in reducing the conflict between ID, Ego and Super Ego?

\section{Methodology}

The sample was given training in Self-Hypnosis with the 
following Affirmations to reduce the conflict between ID, Ego and Super Ego.

1) I will have a constant check on ID so that my Ego lies low.

2) I will listen to my Super Ego when ID empowers my mind.

3) I will observe my inner conflicts carefully in order to calm my mind.

4) I will have a check on my anxiety.

5) I will think positive to uphold my self-esteem.

These five affirmations were repeated by the sample every day closing their eyes sitting in a comfortable position for six weeks. To begin with the sample was given a questionnaire to evaluate their ID, Ego and Super Ego level consisting of relevant statements. The training was carried out for six weeks. At the end of the third week they were given the same questionnaire to find whether the measure of ID, Ego and Super Ego equalized. Further the training was carried out for the remaining three weeks. At the end of six weeks, the same questionnaire was given again to measure the levels of ID, Ego and Super Ego to find any improvement.

\section{Findings of the Study}

The findings show that there is no significant improvement in the internal conflict from the initial training period up to three weeks as the "t" value was found to be less than the table value but the " $\mathrm{t}$ " value was found to be significant from the initial training period up to the completion of the training. The result shows that longer the self hypnosis training period better is the balance between ID, Ego and Super Ego and lesser would be the inner conflict (Table 1).

\section{Conclusions}

ID, Ego, and Super-Ego are the three parts of the "psychic apparatus" defined in Sigmund Freud's structural model of the psyche. A simple model based on the interaction of Ego with ID and Super Ego as represented.

Table 1. To show the significant difference between the pre and post self hypnotic training sessions of the experimental group.

\begin{tabular}{lcccc}
\hline $\begin{array}{c}\text { Psychological } \\
\text { variable }\end{array}$ & $\mathrm{N}$ & $\begin{array}{c}\text { Type of } \\
\text { test }\end{array}$ & Training time & $\mathrm{t}$ \\
\hline & Pre & 3 weeks & 1.76 \\
& & Post & & \\
$\begin{array}{c}\text { ID, Ego and Super } \\
\text { Ego }\end{array}$ & 10 & Pre & \\
& & 6 weeks & $3.15^{* *}$ \\
& & Post & \\
\hline
\end{tabular}

${ }^{*} \mathrm{p}<0.05, \stackrel{* *}{*} \mathrm{p}<0.01,{ }^{* * *} \mathrm{p}<0.001, \mathrm{~N} . \mathrm{S}=$ not significant.

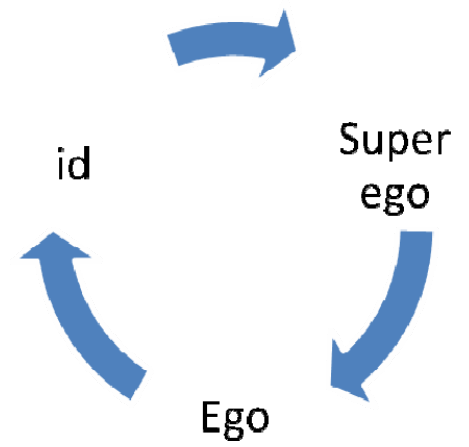

A regular practice of Self-Hypnosis followed by affirmations would improve the conflict between ID, Ego, and Super Ego which could be diagrammed as follows,

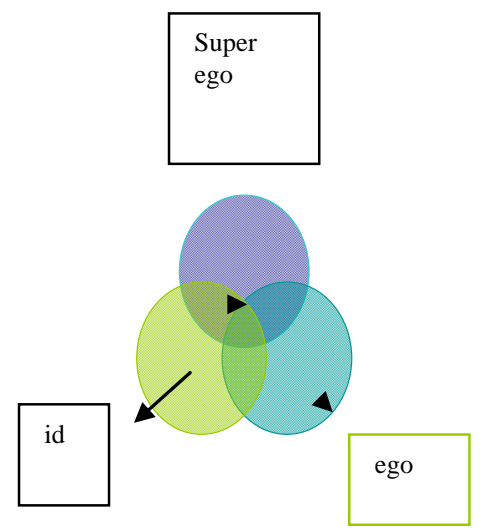

According to the model the ID, Ego and Super Ego are mostly on the same level showing a balance between the three. It is said that Meditation or Self hypnosis help to get back into balance and has an amazing effect on sub-conscious or to find out episodes of past lives. Mental disorders like phobia, anxiety, depression and compulsions arise due to the conflict constantly occurring between ID, Ego and Super Ego. Hence Erickson (1956) [3] pointed out that hypnotic techniques followed in psychoanalysis help to explore the reasons for such disorders and to find a probable solution to overcome it. Self-Hypnosis with affirmations has the following benefits.

1) Understanding of "repression": the therapy gives central importance to the understanding of the manner in which the person uses repression for handling conflict.

2) Establishing intra psychic harmony by developing awareness of the role of the ID, reducing over compliance with Super Ego, and by strengthening the Ego.

3) Explores unconscious motivation, conflicts, and desires.

4) Improves human nature being the most complex as the human psyche is embedded in the past, present, and future; it consists of conscious and unconscious elements, rational and irrational impulses, masculine and feminine tendencies, which are all contradictory tendencies. Thus 
these tendencies remain in harmony.

5) Improves positive interpersonal relations of love and social motivation have a significant role.

6) Improves Ego functioning which is significant rather than ID.

\section{REFERENCES}

[1] S. Freud, “The Ego and the Id, XIX,” 2nd Edition, Hogarth Press, Richmond, 1923.
[2] E. Coue, "Self Mastery through Conscious Auto- suggestion,” Encyclopædia Britannica, 2010.

[3] E. H. Erikson, “The Problem of Ego Identity,” Journal of the American Psychoanalytic Association, Vol. 4, 1956, pp. 56-121. 